\title{
Information and Predictive Oscillators of Energy Earthquakes
}

\author{
Giulio Riga', Paolo Balocchi ${ }^{2}$ \\ ${ }^{1}$ Independent Researcher, Lamezia Terme, Italy \\ ${ }^{2}$ Independent Researcher, Modena, Italy \\ Email: giulio.riga@tin.it
}

How to cite this paper: Riga, G. and $\mathrm{Ba}$ locchi, P. (2019) Information and Predictive Oscillators of Energy Earthquakes. Open Journal of Earthquake Research, 8, 201-222. https://doi.org/10.4236/ojer.2019.83012

Received: June 6, 2019

Accepted: August 6, 2019

Published: August 9, 2019

Copyright (c) 2019 by author(s) and Scientific Research Publishing Inc. This work is licensed under the Creative Commons Attribution International License (CC BY 4.0).

http://creativecommons.org/licenses/by/4.0/

\begin{abstract}
Through the analysis of different seismic sequence, it is possible to observe that, before a strong earthquake, the values of longitude and latitude of the shocks begin to fluctuate in an abnormal way. The amplitude increases beyond the normal level just before the earthquake occurs, forming an easily identifiable pattern. The purpose of this study is to analyze the anomalous fluctuations of values the longitude and/or latitude during seismic activity and to carry out some simple procedures, reliable enough for the search of attention signals that precede a strong earthquake and in some cases its epicenter. The retrospective analyses carried out on many sequences of earthquake data occurred in different tectonic environments, have shown how all earthquakes were preceded by abnormal fluctuations in the values of longitude and/or latitude. This study describes the graphic and calculation procedures with the aim of obtaining information on the occurrence of the large earthquakes studied. In particular, we have noticed that the earthquake occurs after extreme levels of fluctuation are reached in the series of values analyzed. Through this model, it is possible to recognize elements discriminated during the evolution of the seismic sequence and using them as possible precursors of short-term, strong earthquakes.
\end{abstract}

\section{Keywords}

Mainshock, Foreshock, Aftershock, Seismic Sequence, Clustering, Energy Earthquakes

\section{Introduction}

Although earthquake forecasting is a highly controversial issue, scientists are continuing to find valuable precursors of earthquakes. Among various precursors, seismicity changes play an important role in intermediate-term forecast 
study and have been tested for a long period [1].

By analysing a seismic sequence, it is possible to observe significant fluctuations in the seismological parameters [1] [2] [3], as longitude and/or latitude values recorded shortly before major earthquakes (Figure 1 ). These fluctuations generally occur in a disorderly manner, but through analysis with appropriate calculation procedures and graphics it is possible to identify patterns that allow you to understand the processes that precede major earthquakes.

In the general scheme, we can see that, before a strong earthquake, the amplitude of fluctuation of the values of longitude and/or latitude tends to increase and then decrease, showing how earthquakes tend to group according to clusters [1] [2], whose seismogenic source may be also different from the one that generates the mainshock [2] [3]. This study describes, as usually, a strong earthquake occurs after the amplitude of the fluctuation reaches the maximum value that depends on the size of the area analyzed and the geometry of seismogenic structures.

The following analysis procedures have been elaborated after analysing the seismic sequences of 120 earthquakes of $M \geq 7$ and 27 of $M=5.8-7.0$ occurred in various parts of the world and using the earthquake catalogues of the United States (USGS) [4], Italy (INGV) [5], and Japan (NIED) [6].

In this study, we have analysed the sequences of major earthquakes, classifying the anomalies of the fluctuation of the values of longitude and latitude. We also propose some graphic and calculation procedures to analyse the values of longitude, latitude and magnitude in the different states in which they can move through time, in order to identify the signals of possible precursors that precede strong earthquakes.

Through the proposed model described this paper, it is possible to study the seismicity of an area and obtain information during the evolution of the seismic sequence. This information can be used as possible short-term precursors of strong earthquakes.

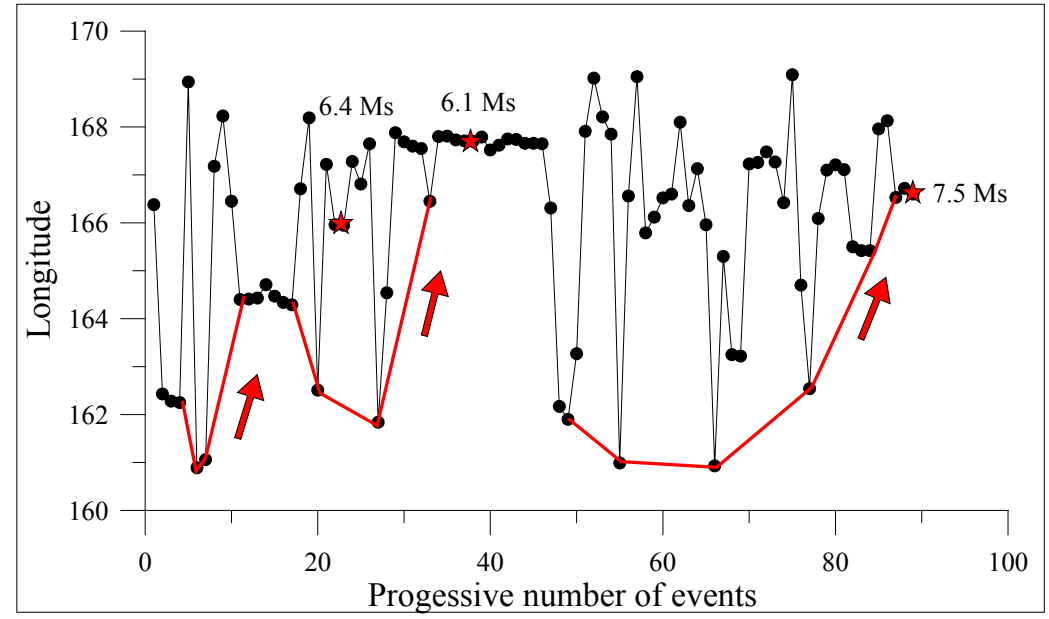

Figure 1. Fluctuation of longitude values. The red lines indicate the fluctuations, the arrow indicates the direction of migration of the values. 


\section{Methodology}

\subsection{Trendlines Model}

Analysis of the longitude and latitude value series shows abnormal fluctuations before major earthquakes, highlighting the shift from a tendency to disperse values to its clustering or vice versa.

The process of seismicity clustering, and therefore its spatial-time distribution, can be interpreted as a preparatory process for the nucleation of a strong earthquake, in relation to the secondary structures and the main seismic source [7] [8] [9]. Some authors point out that earthquakes belonging to different clusters are representative of main and secondary seismic sources [10] [11].

The analysis of seismic sequences shows an evident situation of dispersion of longitude and latitude data, which over time, evolve towards an increasingly structured configuration just before the main event and very structured after the seismic event (aftershock phase).

Moreover, after the formation of the absolute minimum and maximum (or vice versa) of each fluctuation cycle, it is possible to obtain information on the future evolution of the values, apparently random, but which could be the result of the interaction of several close seismogenic sources, and therefore of the earthquakes associated with them [12] [13] [14].

The first operation consists in identifying, in the series of values, the absolute maximum and minimum of the fluctuation cycle, which represent the points of maximum dispersion. The second operation to be performed is to identify on the graph of the values of longitude (Figure 2) and/or latitude, the relative maxima and minima (blue and red circles). The third operation consists in joining the maximum and minimum values with segments (blue and red lines, respectively).

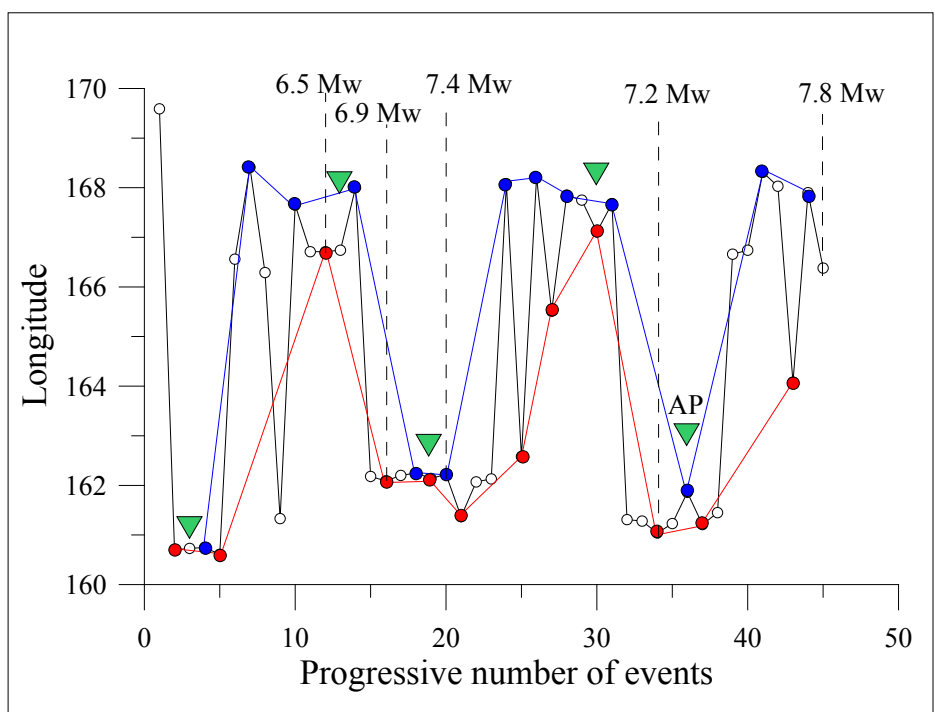

Figure 2. Fluctuation of longitude values. The blue and red circles indicate the maxima and minima of fluctuation respectively, the blue and red lines unite the maxima and minima respectively, the green triangles indicate the points of attention. 
The areas where the blue and red circles tend to approach can be considered as a point of attention (AP) from which the amplitude of the fluctuations tends to increase. The succession of AP and abnormal fluctuations show how energy earthquakes are partially activated by previous events.

In general, it can be assumed that for large earthquakes $(M>6)$ the process essentially consists of a repeated and progressive rupture along the same fault, rather than the creation of a new fault segment [13] [14].

The detailed analysis of the seismic sequences has highlighted the formation of some patterns of fluctuation of the values of longitude and/or latitude that can be grouped into the following categories:

\section{1) CATEGORY A}

In this category, it can be noticed how after the abrupt variation of the longitude values, the series develops along an orderly and regular sequence of values.

In Figure 3, we can see how in general, before a strong earthquake (mainshock or foreshock), the longitude values vary in a wide range, until they reach a concentration of values along a narrow band delimited by two trendlines (upper and lower), starting from foreshock (clustering). This clustering is recorded up to the longitude value of the epicenter where the mainshock of the sequence is nucleated. This category, in which there is a progressive migration in the direction of the zone where the main rupture of the fault that triggers the EQ occurs, was founded in $12 \%$ of the sequences analyzed.

In the 2011 earthquake in Japan, the sequence of values covering the time span between the maximum value and the AP, would have led to the initial breakage point with the earthquake of magnitude 7.3 Mw (foreshock) on March $9,2011$.

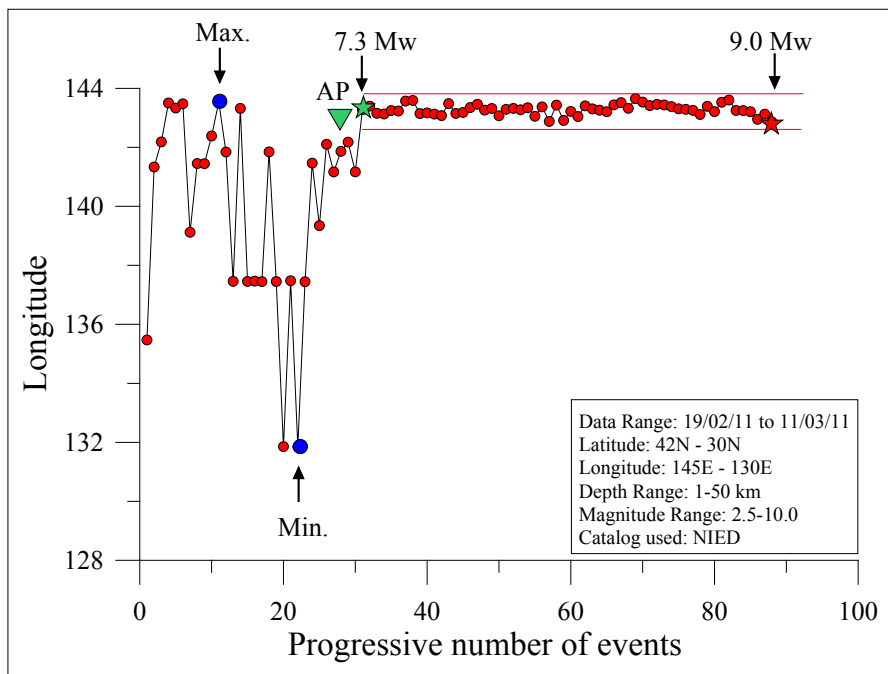

Figure 3. Sequence of longitude values of Japan Earthquake of 11/03/11. The red lines indicate the trendlines, the green triangle indicates the point of attention, the blue circles indicate the absolute maximum and minimum, the green and red stars indicate the foreshock and the mainshock respectively. 
The second sequence, which developed in a small area, would have contributed to reach a level of tension such as to trigger the main earthquake that occurred two days later.

A second AP (Figure 4) can be envied by tracing the line joining an energy event (mainshock, foreshock or afteshock) and the subsequent earthquake of greater magnitude that must be preceded and/or followed by a lower maximum magnitude (green circles). The three earthquakes form a small scale Foreshocks-Mainshock-Aftershocks (FMA) pattern [15] [16] [17].

The point of attention is formed when the magnitude values of the following earthquakes, are positioned above the trendline, and comparing them with the maximum value of the previous earthquake, allows you to know the phase of accumulation or energy release in place. In fact, if the magnitude values are below the trendline, we are in an energy storage phase, while if they are above, we are in an energy release phase where some earthquakes represent foreshocks.

A similar fluctuation in the values of longitude and latitude occurred in Italy, during the earthquakes of Perugia in 1997 and L'Aquila in 2009.

Figure 5 shows the fluctuation of the latitude values before the L'Aquila earthquake of 06/04/2009. The foreshock of magnitude 4.0 Mw occurred on $30 / 03 / 2009$ was preceded by a sharp increase in the amplitude of fluctuation of values and then by a fluctuation in a narrow band that can be classified as a clustering of a seismic swarm [18].

Figure 6 shows the time sequence of the magnitude values where, with the green stars, are shown the first and second order foreshocks [19], the point of attention and the FMA scheme that preceded the main earthquake.

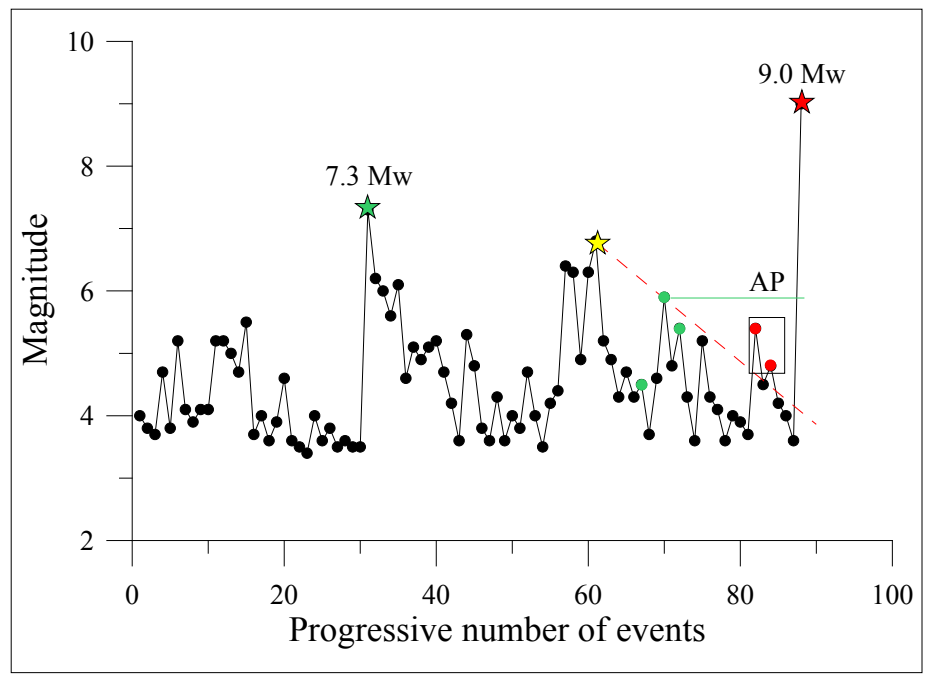

Figure 4. Sequence of magnitude values of Japan Earthquake of 11/03/11. The dotted red line indicates the trendline, the red circles indicate the point of attention, the green circles represent the FMA scheme, the green, yellow and red stars indicate respectively the foreshock, aftershock and mainshock, the box indicates the position of the point of attention, the green line indicates the limit in the seismic sequence between the phase of accumulation and release of energy. 


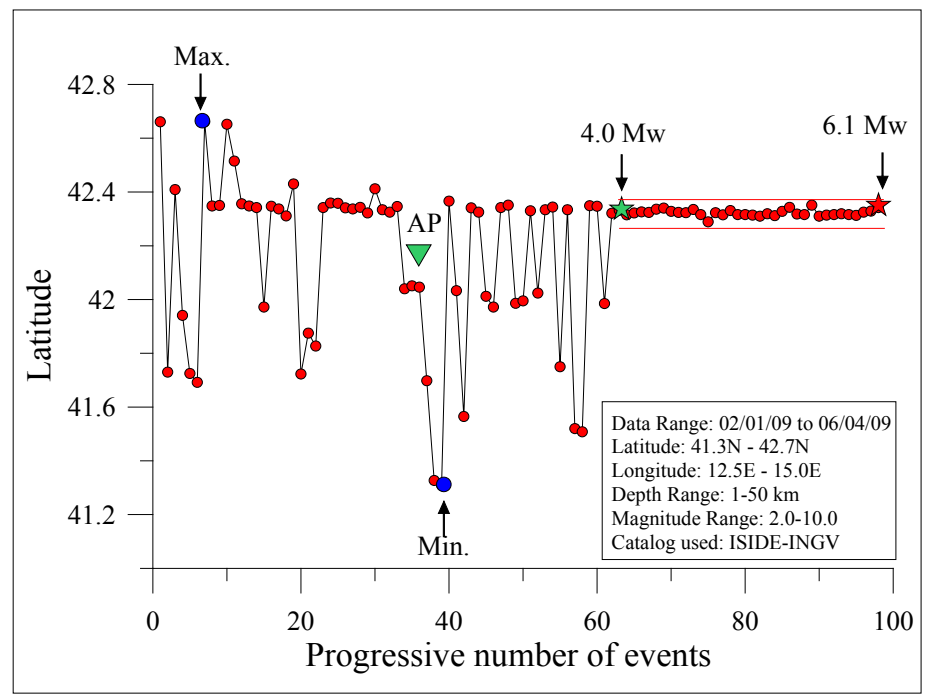

Figure 5. Sequence of latitude values of L'Aquila earthquake of 6/4/2009. The red lines indicate the trendlines, the green triangle indicates the point of attention, the blue circles the absolute maximum and minimum, the green and red stars indicate the foreshock and the mainshock respectively.

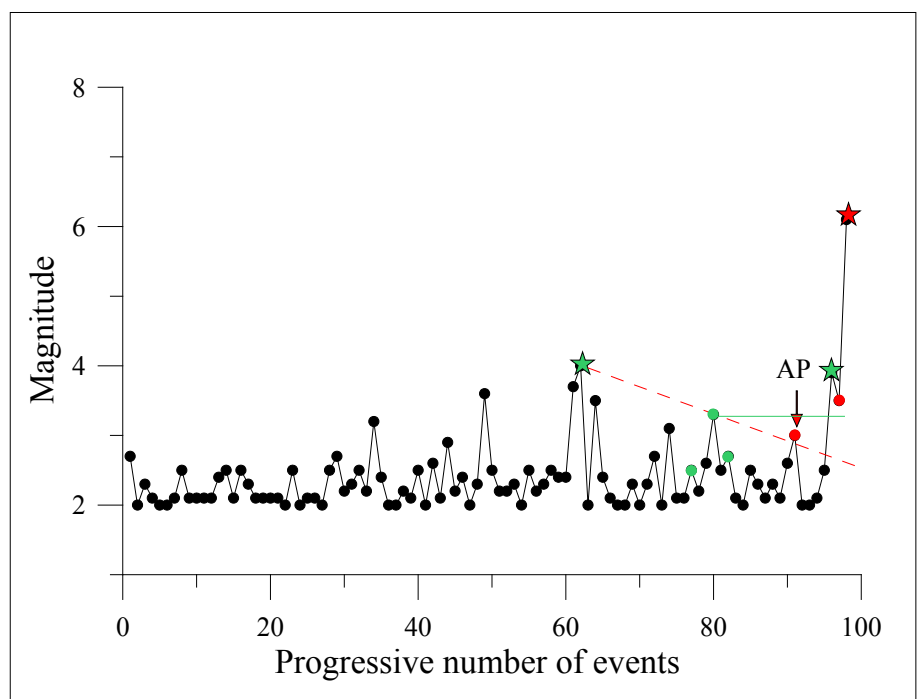

Figure 6. Sequence of the magnitude values of L'Aquila earthquake of 6/4/2009. The dotted red line indicates the trendline, the green star indicates the foreshock, the red star indicates the mainshock. The red arrow indicates the position of the AP, the green line indicates the limit in the seismic sequence between the phase of accumulation and release of energy, the green circles represent the FMA scheme.

\section{2) CATEGORY B}

In this category, founded in $10 \%$ of the analyzed sequences, there is a sharp change in the values of longitude and/or latitude that remains for a given period and a subsequent change in the level of fluctuation after the occurrence of the foreshock.

Figure 7 shows the series of longitude values of the California earthquake of 24/11/1987 with a magnitude of 6.7 Mw. The foreshock of magnitude 6.5 Mw 
occurred just before the mainshock was preceded by a clustering that led to the foreshock of 5.6 Mw of 04/10/1987, with a value of longitude different from that one of the mainshock. Subsequently a wide fluctuation of the values of longitude is recorded until the foreshock of magnitude $6.5 \mathrm{Mw}$ that is placed within a narrow band that also contains the main event. The two earthquakes of magnitude 6.5 $\mathrm{Mw}$ and $6.7 \mathrm{Mw}$ were preceded by points of attention (Figure 8) that formed shortly before.

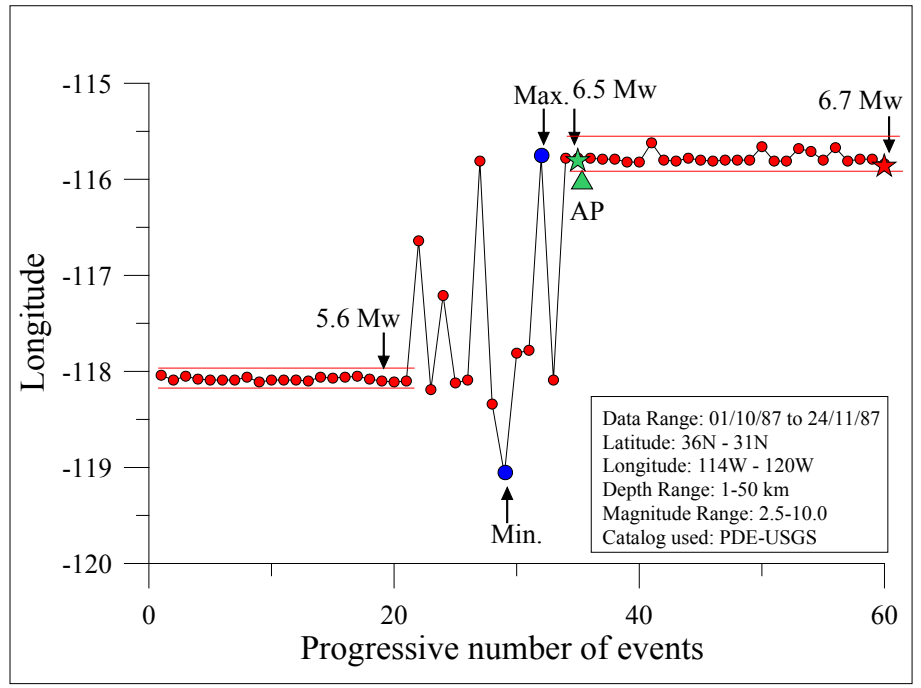

Figure 7. Sequence of the longitude values of the California earthquake of 24/11/1987. The red lines indicate the trendlines, the green triangle indicates the point of attention, the blue circles the absolute maximum and minimum, the green and red stars indicate the foreshock and the mainshock respectively.

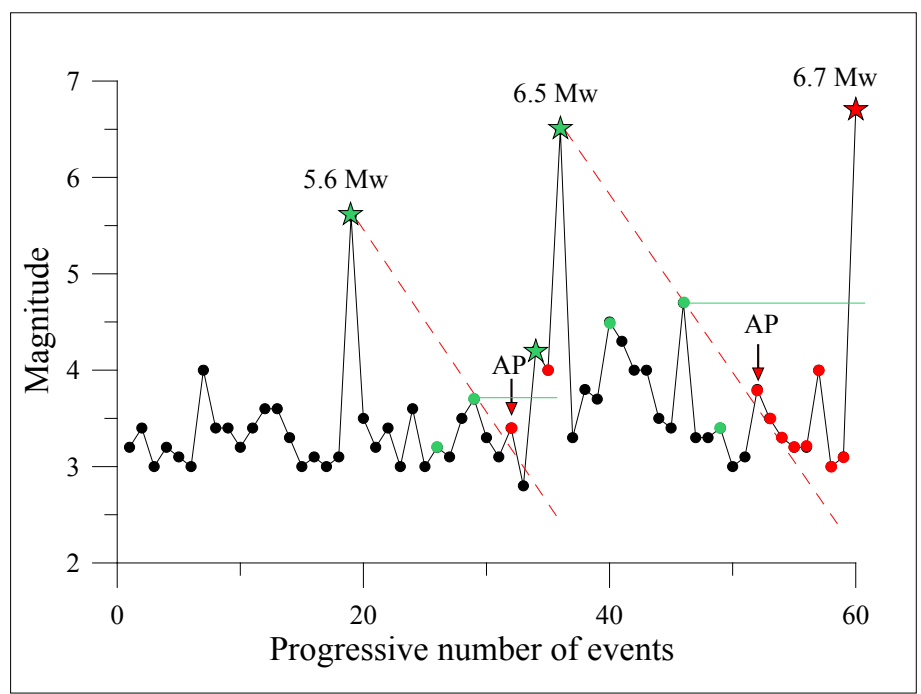

Figure 8. Sequence of the magnitude values of the California earthquake of 24/11/1987. The dotted red line indicates the trendline, the green star indicates the foreshock, the red star indicates the mainshock. The red arrow indicates the position of the attention point, the green line indicates the limit in the seismic sequence between the phase of accumulation and release of energy, the green circles represent the FMA scheme. 


\section{3) CATEGORY C}

This category includes most of the earthquakes analyzed. Longitude and latitude values are placed on different fluctuation levels, where before a strong earthquake there is a sharp fluctuation that causes a change in the longitude value.

Figure 9 shows the sequence of longitude values that preceded the Philippine earthquake of 16/08/1976 and the fluctuation bands obtained by selecting the distant values $\mathrm{L} \leq 0.35$ (longitude deviation). In the final part of the seismic sequence, the longitude values of the earthquakes formed a cluster along a lower band (band A) corresponding to a probable secondary breakage, while the 7.9 Mw mainshock of 16/08/76 was nucleated in the upper band (band B) representing the main breakage (master fault).

Figure 10 shows the series of magnitude values. It is noted that the most energetic earthquake was preceded by two foreshocks respectively of first and second order [19] of magnitude 6.7 Mw (07/06/76) and 6.2 Mw (26/07/76).

Figure 11 and Figure 12 show the sequences of the latitude values of the Vanuatu earthquake of $05 / 12 / 2018$ with a magnitude of $7.5 \mathrm{MW}$ and of the Indonesian earthquake of 4/11/2012 with a magnitude of $8.6 \mathrm{MW}$ in which we note a wider fluctuation of latitude values before energy earthquakes than the narrow fluctuation band into which the latitude value of the strongest earthquakes falls.

\subsection{Oscillators}

An aspect of great importance in the analysis of the historical series of values of magnitude, longitude and latitude consists in the identification of anomalies that anticipate a cycle of energy release or a strong earthquake and therefore, allow to report critical phases.

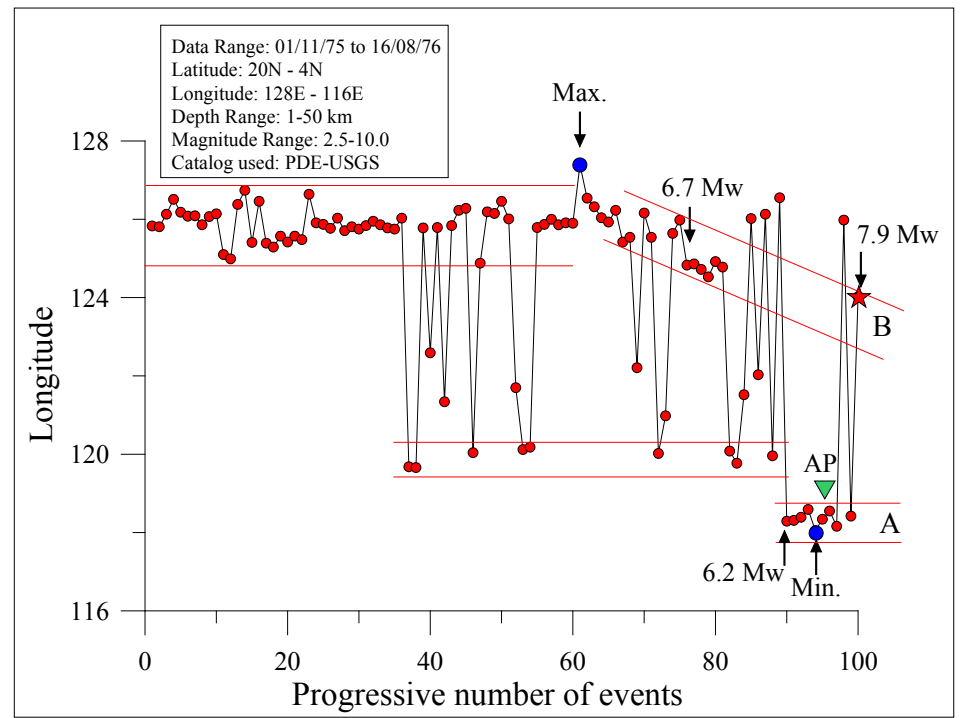

Figure 9. Sequence of the longitude values of the Philippine earthquake of 16/08/76. The red lines indicate the trendlines, the green triangle indicates the point of attention, the blue circles the absolute maximum and minimum, the red star indicates the mainshock. 


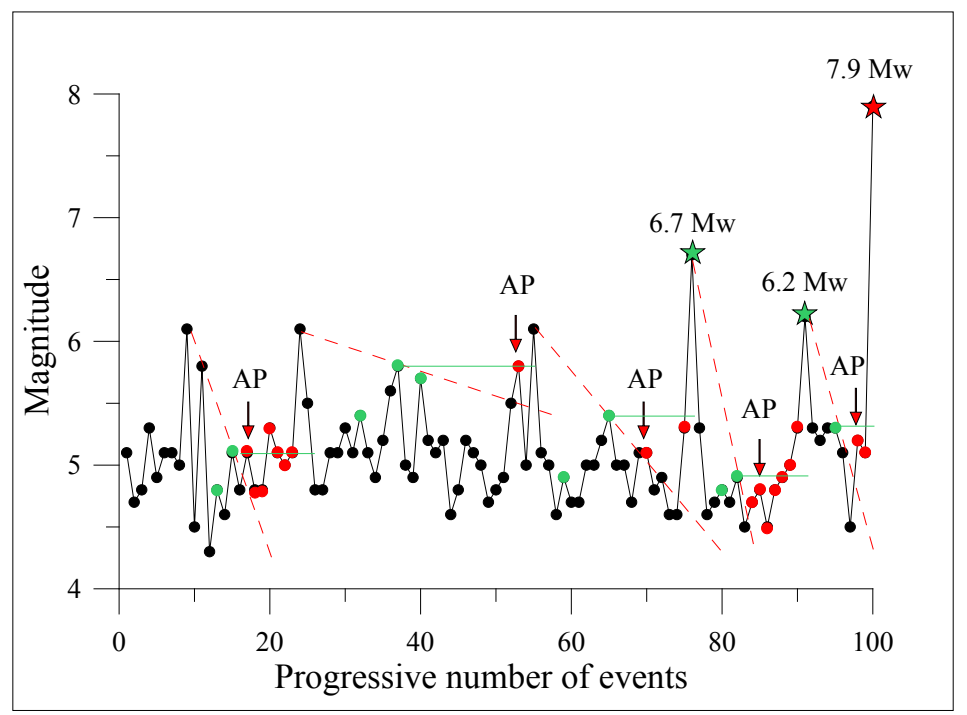

Figure 10. Sequence of the magnitude values of the Philippines earthquake of 16/08/76. The dotted red line indicates the trendline, the green star indicates the foreshock, the red star indicates the mainshock. The red arrow indicates the position of the attention point, the green line indicates the limit in the seismic sequence between the phase of accumulation and release of energy, the circles of color green represent the FMA scheme.

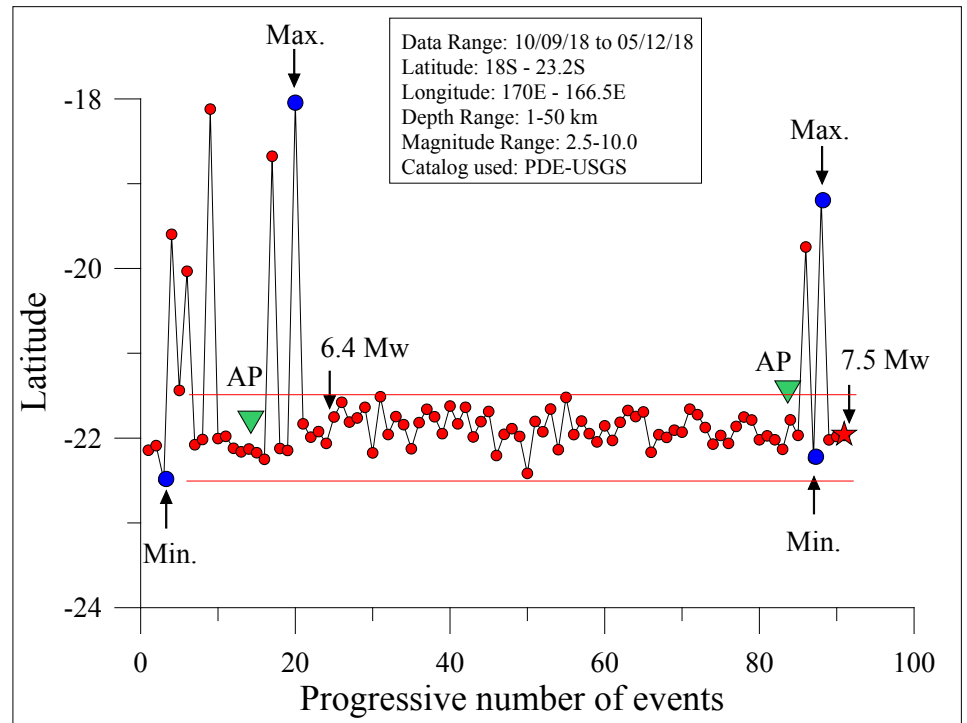

Figure 11. Sequence of the latitude values of the Vanuatu earthquake of $05 / 12 / 18$. The red lines indicate the trendlines, the green triangle indicates the point of attention, the blue circles the absolute maximum and minimum, the red star indicates the mainshock.

Oscillators are essential tools for the analysis of seismic sequences capable of providing useful information to examine and interpret the sequences, in order to forecast short-term changes based on space-time of smaller events.

The oscillators are represented by curves, obtained from partially complex formulas, which oscillate around a central value or between a maximum value (top) and a minimum value (bottom) that highlight the different phases of the seismic sequence that develop over time. 


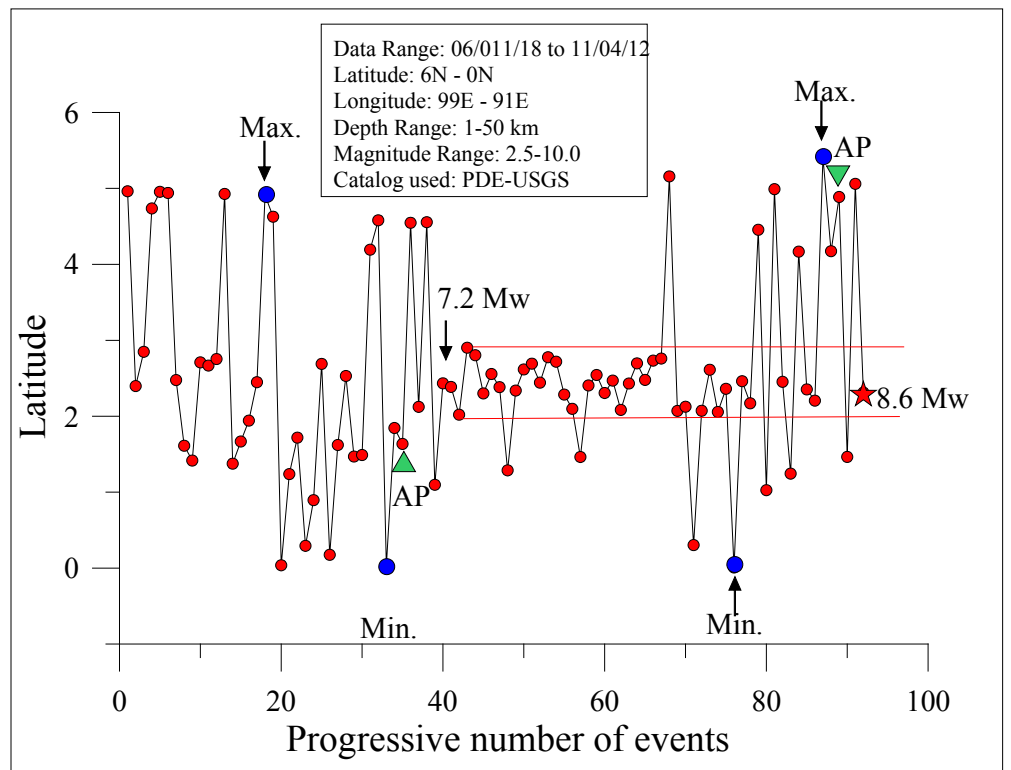

Figure 12. Sequence of the latitude values of the Indonesia earthquake of $11 / 04 / 12$. The red lines indicate the trendlines, the green triangle indicates the point of attention, the blue circles the absolute maximum and minimum, the red star indicates the mainshock.

\subsubsection{Latitude Longitude Magnitude Oscillator (LLMO)}

The LLMO oscillator provides information on when an earthquake can occur, using the time series of latitude or longitude or magnitude values.

Figure 13 shows how, during a short-term phase, values move within channels usually marked by parallel or otherwise inclined trendlines, whose slope reflects the speed of the values compared to time.

This type of trend has a great importance because the observation of several sections and their comparison allows to define an informative signal.

In fact, this feature allows us to understand that, when the values seem to no longer respect the trendlines within which they move, we can expect the occurrence of a more or less strong earthquake.

Sometimes the earthquake is preceded by trendlines with a smaller slope during the formation of a cluster and the values are more structured and close to that one of the main shock.

In particular, in the final part, when the system enters a critical phase, the values tend to get very close.

In some sequences, the values in the period before the mainshock, are taken out of the trendlines or their convergence.

The point where the oscillator deviates from the current trend and the values emerge from the trendlines is selected as a warning signal.

In Figure 14, the LLMO oscillators calculated using the values of latitude, longitude and magnitude are reported. It is noticed as the final stretch of the oscillator develops with a more inclined trend in comparison to the previous one with the values that are carried out by the trendlines. 


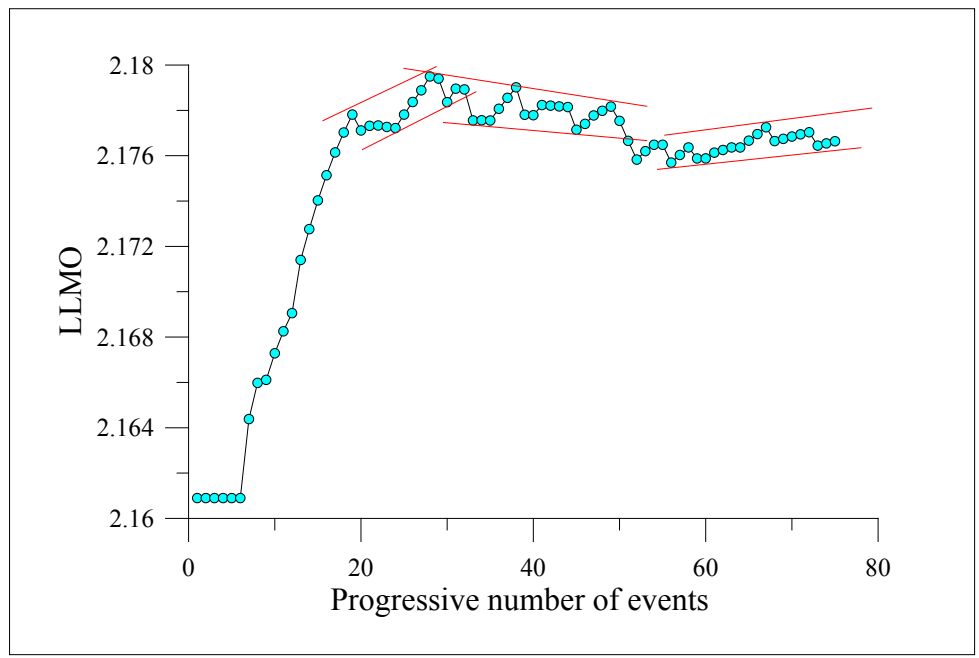

Figure 13. LLMO oscillator for longitude values. The red lines indicate the trendlines.

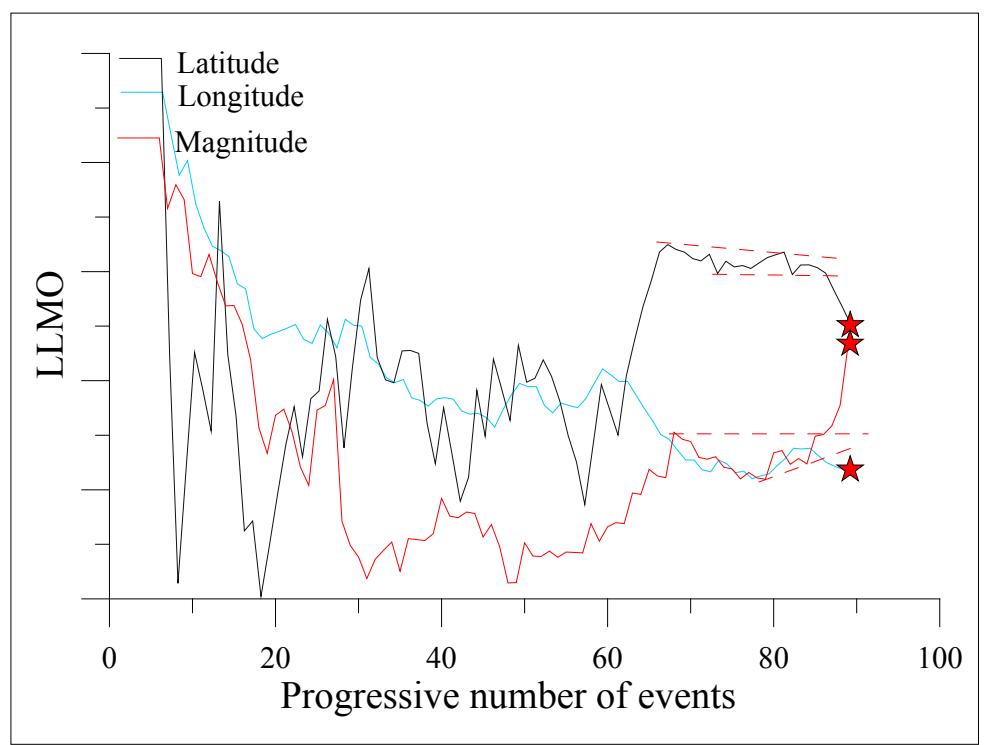

Figure 14. LLMO oscillator relative to latitude, longitude and magnitude values. The dashed red lines indicate the trendlines.

In Figures 15-18, the overlap of the LLMO oscillator on the series of longitude values, highlights the periods, where there are anomalous fluctuations of the values and/or approaching that can be assumed as attention signals.

The formula for calculating the LLMO oscillator is as follows: where:

$$
\begin{gathered}
A=\ln \left(M_{n}-\mathrm{LLMO}_{n-1}\right) \\
B=\sum_{1}^{n} A \\
\mathrm{LLMO}=\sqrt{\frac{B}{n}}
\end{gathered}
$$




$$
\mathrm{LLMO}=\sqrt{\frac{\sum_{1}^{n} \ln \left(M_{n}-\mathrm{LLMO}_{n-1}\right)}{n}}
$$

$M=$ magnitude, longitude or latitude;

$n=$ number of data;

for $n=1 \mathrm{LLMO}_{(\mathrm{n}-1)}=0$

The first five LLOM values are assumed to be equal to the sixth value, in order to make the graph easier to read trends:

$$
\mathrm{LLMO}_{(1-5)}=\operatorname{LLMO}_{(6)}
$$

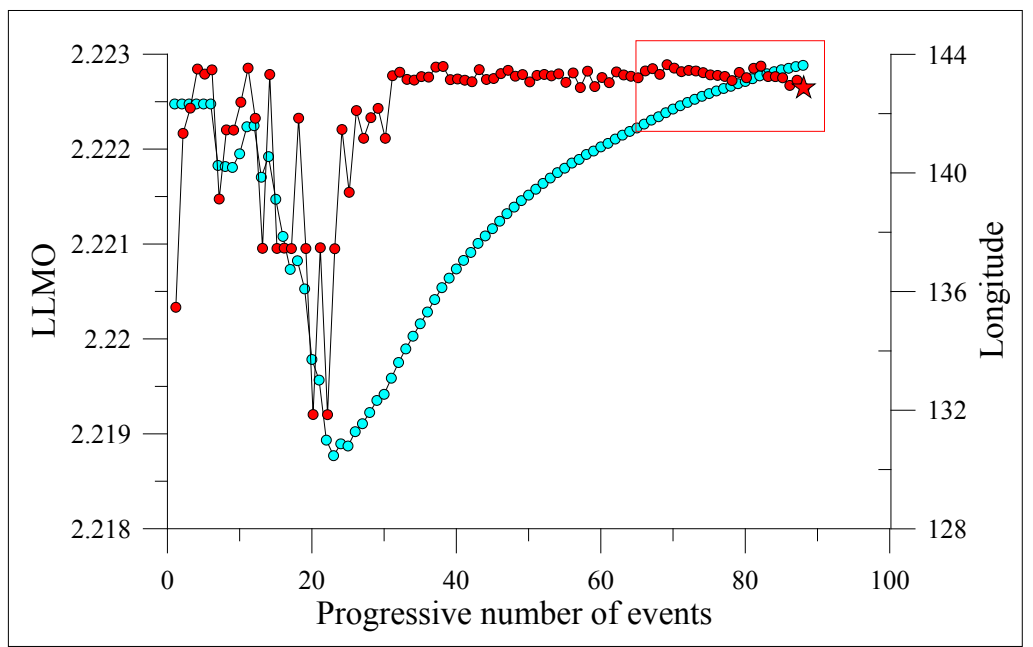

Figure 15. Japan Earthquake of 11/03/2011. LLMO oscillator relative to longitude values. The red box indicates the peridus in which the values of the oscillator tend to approach.

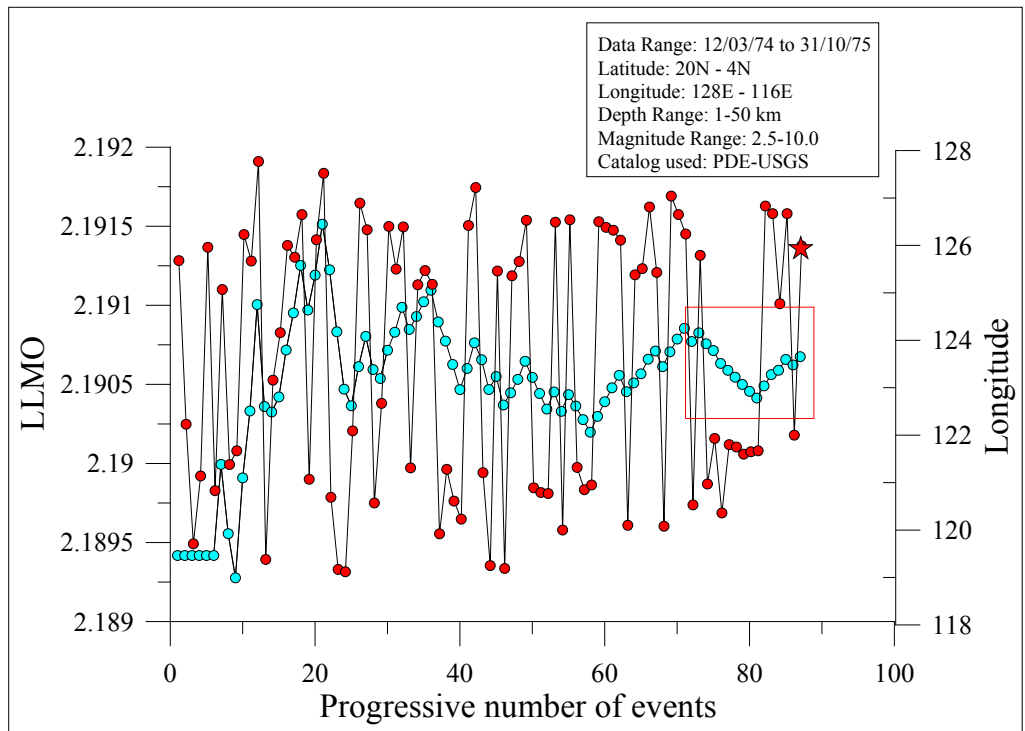

Figure 16. Philippines Earthquake of 31/10/1975. LLMO oscillator relative to longitude values. The red box indicates the period in which the values of the oscillator tend to approach. 


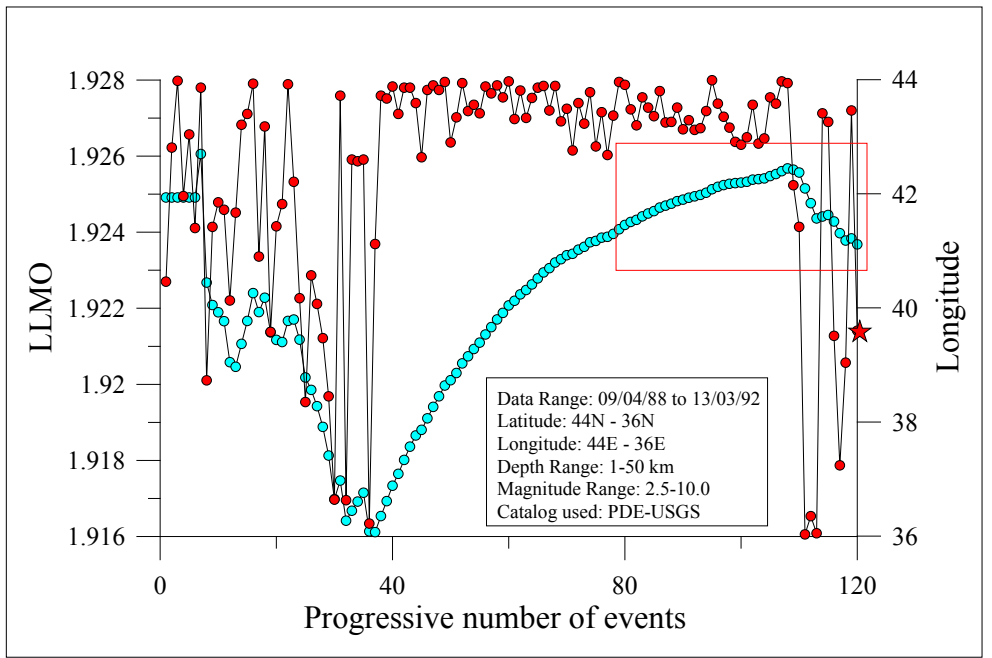

Figure 17. Turkish Earthquake of 13/3/1992. LLO oscillator relative to longitude values. The red box indicates the period in which the values of the oscillator tend first to approach and then to move away (with the increase of the inclination of the oscillator) due to the effect of the wide fluctuation of the values that precedes the earthquake.

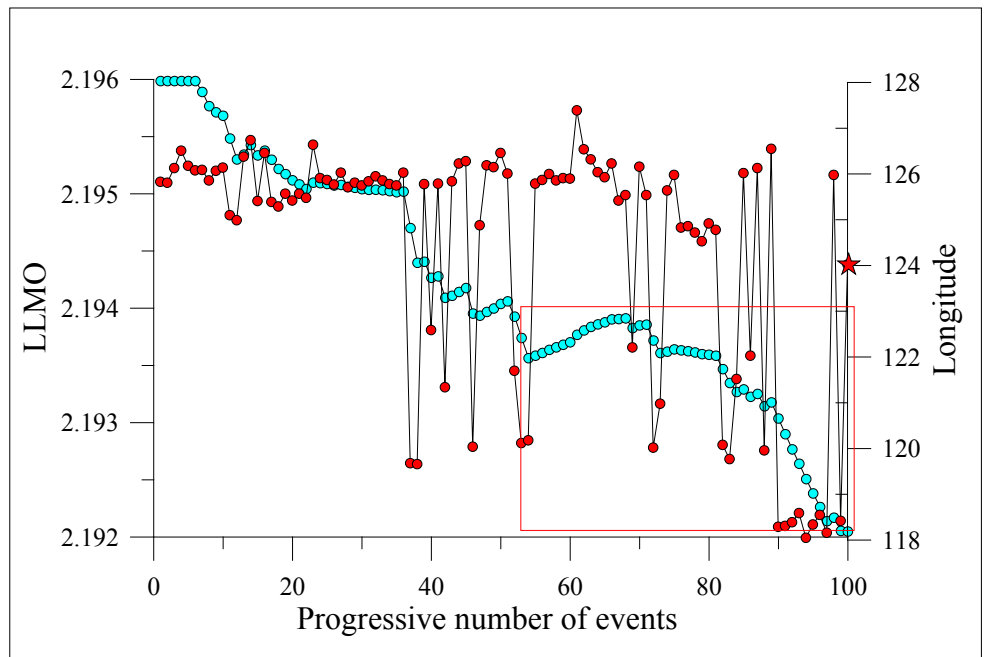

Figure 18. Philippines Earthquake of 16/08/1976. LLMO Oscillator related to longitude values. The red box indicates the period in which the values of the oscillator tend first to approach and then to move away (with the increase of the inclination of the oscillator) due to the effect of the wide fluctuation of the values that precedes the earthquake.

Table 1 shows a brief example of the calculation of the LLMO oscillator.

\subsubsection{Multiple Moving Averages (MMA)}

The MMA is a variant of Guppy's Multiple Moving Average (GMMA) [20] which identifies significant trend changes and their strengths on the base of two sets of moving averages of different time amplitudes.

The moving averages used for the MMA are:

- Short-term: the first series of moving averages has a relatively short period of time. The period of events or days or months $(\mathrm{N})$ used in these moving averages is $3,5,7,10,12$ or 15 . 
Table 1. Calculation procedure.

\begin{tabular}{cccccc}
\hline $\mathrm{n}$ & $\mathrm{M}$ & $\mathrm{A}$ & $\mathrm{B}$ & $\mathrm{LLMO}$ & LLMO $_{(1-10)}$ \\
\hline 1 & 4.9 & 1.5892 & 1.5882 & 1.2606 & 1.1710 \\
2 & 5 & 1.3189 & 2.9081 & 1.2058 & 1.1710 \\
3 & 5.1 & 1.3594 & 4.2676 & 1.1927 & 1.1710 \\
4 & 4.6 & 1.2259 & 5.4935 & 1.1719 & 1.1710 \\
5 & 4.9 & 1.3158 & 6.8094 & 1.1669 & 1.1710 \\
6 & 5.3 & 1.4190 & 8.2284 & 1.1710 & 1.1710 \\
7 & 5.1 & 1.3683 & 9.5968 & 1.1708 & 1.1708 \\
8 & 4.6 & 1.2323 & 10.8291 & 1.1634 & 1.1634 \\
9 & 4.6 & 1.2344 & 12.0635 & 1.1577 & 1.1577 \\
10 & 4.8 & 1.2926 & 13.3561 & 1.1556 & 1.1556 \\
\hline
\end{tabular}

- Long-term: the second series of moving averages uses longer time periods. The period of events or days or months $(\mathrm{N})$ used in these moving averages is $30,35,40,45,50$ or 60 .

- Short-term: is the average of the short-term moving averages 3, 5, 7, 10, 12 (beginning of 15 periods).

- Long-term: is the average of the long-term moving averages $30,35,40,45,50$ (beginning of 50 periods).

The following formula is used to calculate the MMA is:

$$
M M A=M M A_{(n-1)}+S F \cdot\left[V_{(n)}-M M A_{(n-1)}\right]
$$

where:

$\mathrm{V}_{(\mathrm{n})}=$ refers to the value of magnitude, longitude, latitude or LLMO;

$S F$ refers to a smoothing factor, which is calculated as follows:

$$
S F=\frac{2}{N+1}
$$

where $N$ represents the period used to calculate by the MMA.

The first $\mathrm{MMA}_{(\mathrm{N})}$ value of each period is equal to the value of $\mathrm{V}_{(\mathrm{N})}$.

Table 2 and Table 3 show a brief example of the calculation of the MMA.

MMA are applied as an overlap in the LLMO oscillator graph, preferably obtained from the set of magnitude values.

The use of several moving averages at the same time, allows to obtain attention signals and avoid some false signals that the single averages create.

Figure 19 shows the twelve moving averages plotted on a graph of the LLMO oscillator, where the green moving averages represent the short-term trend and the red moving averages the long-term trend, while Figure 20 shows the average of the short-term moving averages in relation to the LLMO oscillator and the magnitude values of the seismic sequence.

The areas during which the different moving averages overlap, move away or approach, represent signals of attention. The information and attention signals provided by the Multiple Moving Averages (MMA) are as follows: 
Table 2. Calculation procedure for $\mathrm{N}=3, \mathrm{MMA}_{(3)}=2.7$ and $\mathrm{SF}=0.5$.

\begin{tabular}{llc}
\hline $\mathrm{n}$ & $\mathrm{V}_{(\mathrm{n})}$ & $\mathrm{MMA}_{(3-10)}$ \\
\hline 1 & 2.3 & -- \\
2 & 2.2 & -- \\
3 & 2.7 & 2.7 \\
4 & 2.1 & 2.4 \\
5 & 2.0 & 2.2 \\
6 & 2.6 & 2.4 \\
7 & 2.2 & 2.3 \\
8 & 2.1 & 2.2 \\
9 & 2.2 & 2.2 \\
10 & 2.0 & 2.1 \\
\hline
\end{tabular}

Table 3. Calculation procedure for $\mathrm{N}=5, \mathrm{MMA}_{(5)}=2.0$ and $\mathrm{SF}=0.333$.

\begin{tabular}{llc}
\hline $\mathrm{n}$ & $\mathrm{V}_{(\mathrm{n})}$ & $\mathrm{MMA}_{(5-10)}$ \\
\hline 1 & 2.3 & --- \\
2 & 2.2 & -- \\
3 & 2.7 & -- \\
4 & 2.1 & --- \\
5 & 2.0 & 2.0 \\
6 & 2.6 & 2.2 \\
7 & 2.2 & 2.2 \\
8 & 2.1 & 2.166 \\
9 & 2.2 & 2.177 \\
10 & 2.0 & 2.118 \\
\hline
\end{tabular}

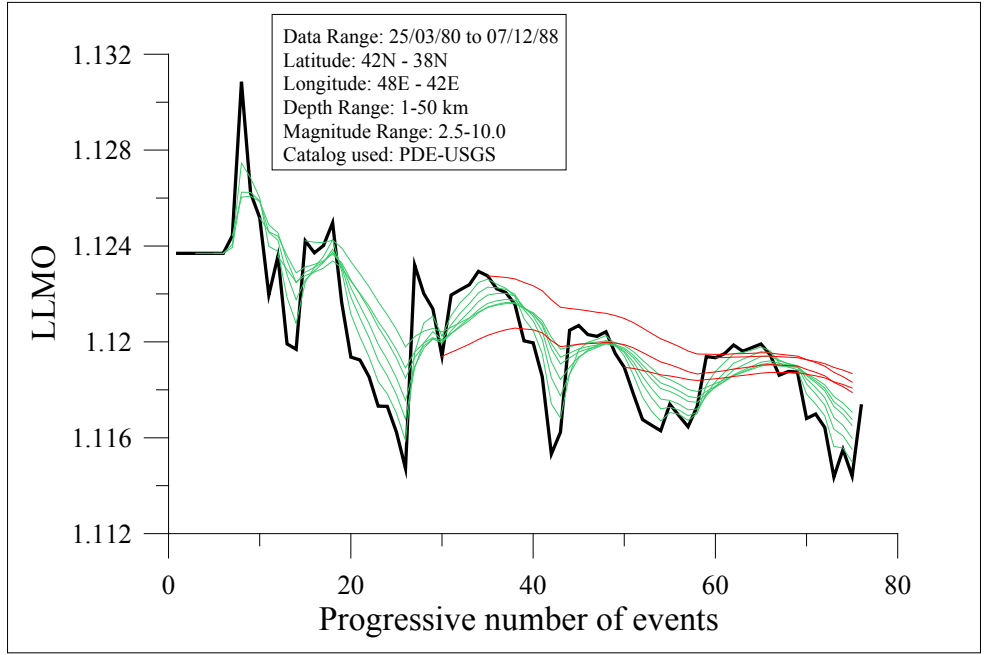

Figure 19. Armenia Earthquake of 07/12/1988. The green and red lines indicate respectively the short and long term multiple moving averages. 


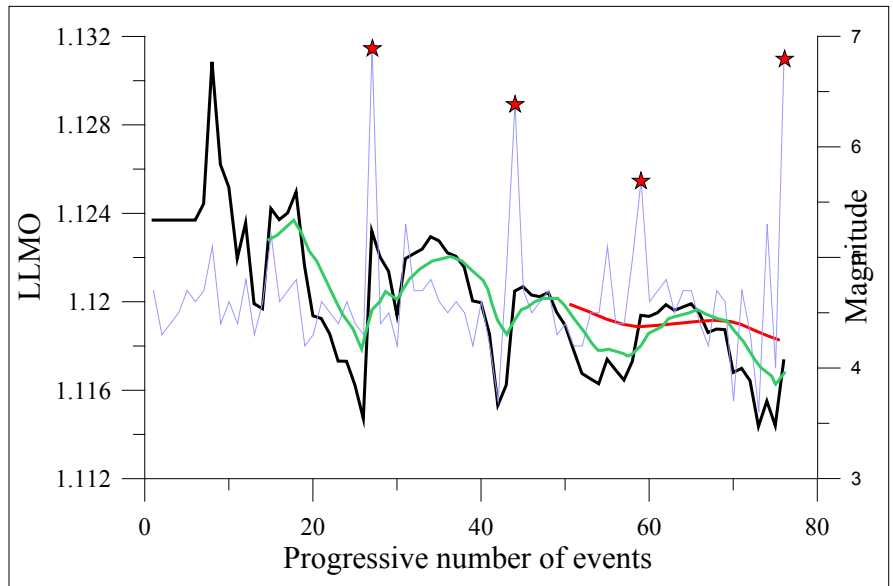

Figure 20. Armenia Earthquake of 07/12/1988. The green and red lines indicate respectively the average of the short and long term multiple moving averages.

- The areas where the short-term averaging group moves above the long-term averaging group indicate that there is a phase of energy release that could end in a major earthquake.

- The areas where the short-term group falls below the long-term group indicate a phase of energy accumulation that could end with a strong earthquake.

- The areas where there is much separation between the averages, indicate that in the area analyzed is underway a phase of release or accumulation of significant energy, with a development of a significant seismicity.

- The areas in which the groups compress each other or cross, indicate that it is possible to invert the phase in progress. In particular, after a period of energy storage, when the lines start to separate it means that the energy storage phase is over and a phase of energy release could begin.

- The areas in which the short term bands approach those of the long term moving averages and become a thread (they stretch out like lines and almost never come back on themselves), indicate the disappearance of the trend and a standby phase in progress. This circumstance is what indicates that an energy event is possible.

- The areas in which there is a strong upward trend and the group of short term averages is carried over the long term ones (but do not cross) and begin to rise quickly, provide a strong signal of the phase in progress (of energy release). The same concept applies to downward trends (energy storage phase).

\subsubsection{Modified Stochastic Oscillator (OSM)}

Modified Stochastic Oscillator [21] [22] uses an moving average to detect attention signals.

This type of oscillator indicates the relative position assumed by the last value of the series analyzed within a given period between 5 and 10 periods that can represent earthquakes, days or months and it is based on the principle that in the phases of rising trend (phase of energy release), the values tend to be stabilized in the upper area of the range and vice versa in the case of falling trend (phase of 
energy accumulation).

The graph of the OSM is therefore represented by two curves that oscillate in the range $0 \%-100 \%$.

The thinner green curve (Figures 21-24) is defined as fast stochastic or 5 -period \% K-line. It is the most sensitive line to the trend of values, therefore it is the fastest and the most reactive.

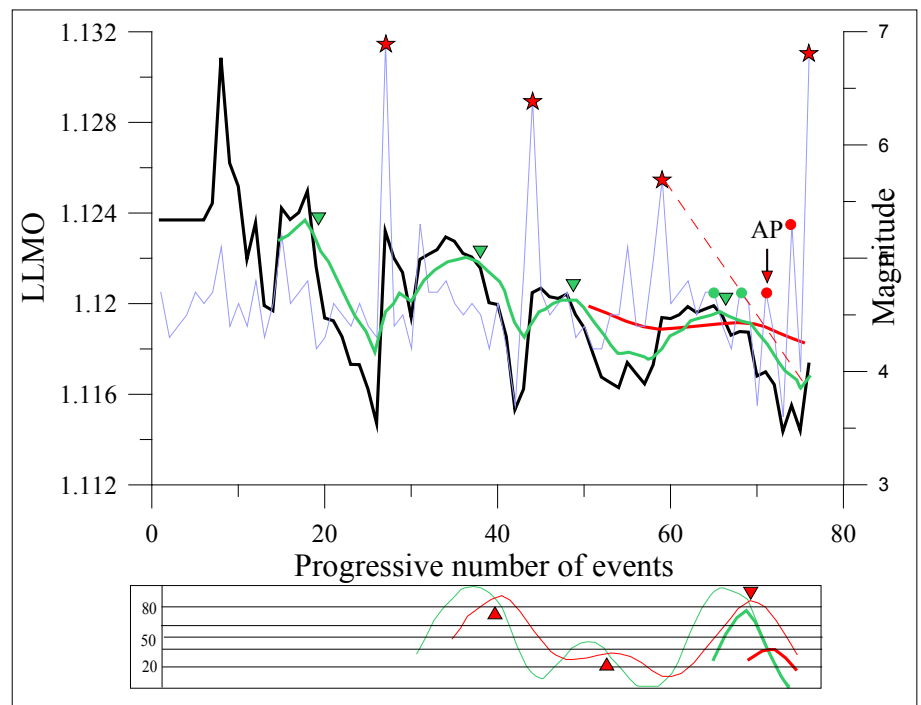

Figure 21. Armenia Earthquake 07/12/1988. Below, the green and red lines of lesser thickness indicate the Modified Stochastic Oscillator respectively at 5 and 10 periods obtained using the average of the short term moving averages $3,5,7,10,12$. The thicker green and red lines indicate the Modified Stochastic Oscillator at 5 and 10 periods respectively obtained using the average of the long-term moving averages $30,35,40,45,50$. The red dotted line indicates the trendline, while the green circles represent the FMA scheme.

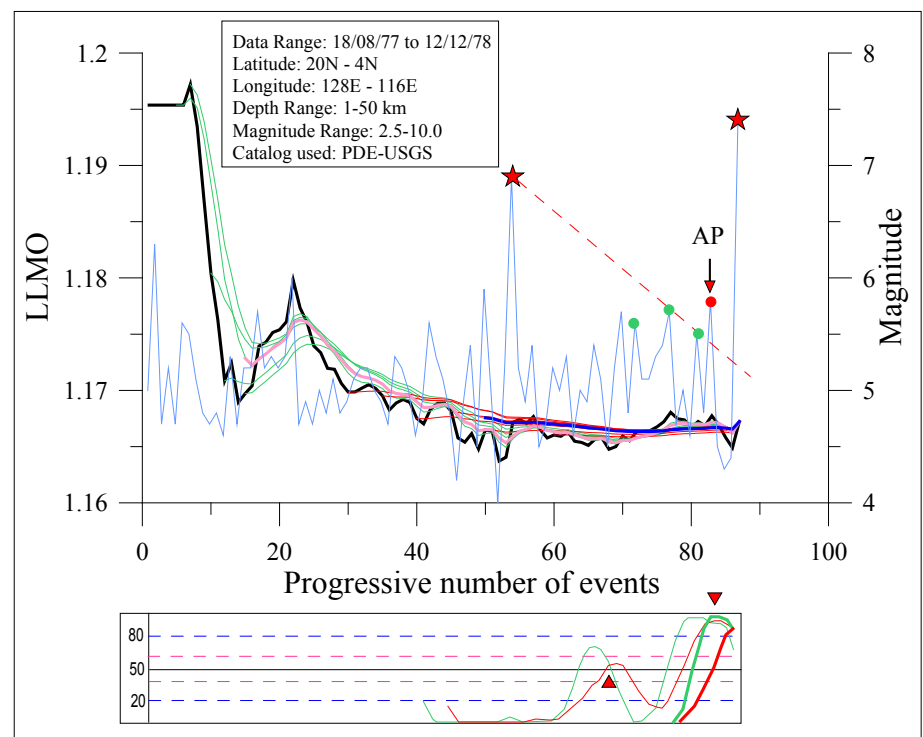

Figure 22. Philippines Earthquake of $12 / 12 / 78$. The red stars indicate the most energetic earthquakes, the triangles and the red arrow indicate the attention signal, the red dotted line indicates the trendline, while the green circles represent the FMA scheme. 


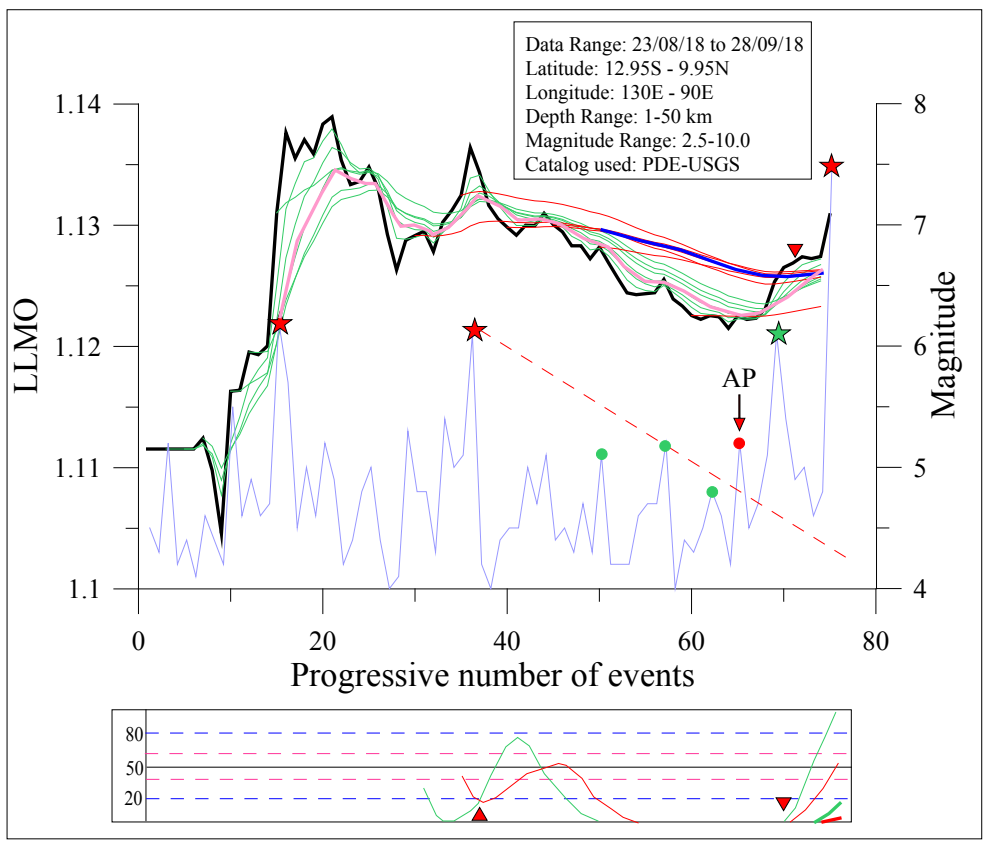

Figure 23. Indonesia Earthquake of 28/08/18. The red stars indicate the most energetic earthquakes, the green star indicates the foreshock, the red triangles and arrow indicate the attention signal, the red dotted line indicates the trendline, while the green circles represent the FMA scheme.

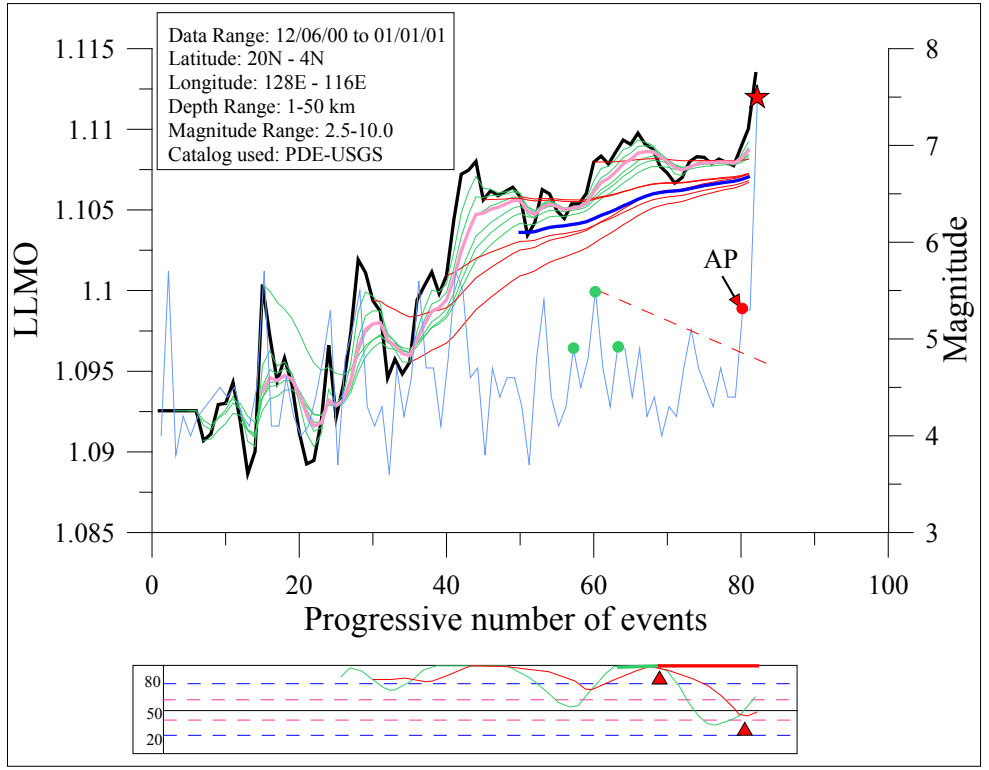

Figure 24. Philippines Earthquake 01/01/01. The red stars indicate the most energetic earthquakes, the triangles and the red arrow indicate the attention signal, the red dotted line indicates the trendline, while the green circles represent the FMA scheme.

The thinnest red curve is called slow stochastic or 10-period D-line \%. It is the slowest and represents the simple moving average of the $\% \mathrm{~K}$-line.

It aims to filter out the erratic movements of the fast stochastic and to generate a crossover effect with the $\% \mathrm{~K}$ line. 
In predictive practice, a first signal of attention is given in cases where the medium-term mean is descending and/or when the $\% \mathrm{~K}$-line crosses the $\% \mathrm{D}$-line and vice versa.

In particular, there is a warning signal, when the $\% \mathrm{D}$-line is increasing, it is in an area greater than $80 \%$ and the K-line is crossed downwards, which simultaneously passes below the value of $80 \%$.

Usually, when the OSM value is less than $20 \%$, it shows an energy storage phase in progress, i.e. a situation that could soon result in the activation of an energy release phase;

when the value of the OSM is higher than $80 \%$ it shows an energy release phase in progress, that is a situation that soon could give rise to the activation of an energy storage phase.

The first step in calculating the OSM is to determine the maximum and minimum values for the period considered.

Then we move on to the calculation of $\% \mathrm{~K}$-line and \%D-line with 5 and 10 periods with the following formulas:

$$
\begin{gathered}
\% K=\frac{C-L_{m}}{H_{m}-L_{m}} \cdot 100 \\
(\% K-\text { line })=\frac{\sum_{1}^{N} \% K}{N}
\end{gathered}
$$

where

$C=$ last value of the period;

$L_{m}=$ minimum value of the period $N$;

$H_{m}=$ maximum value of period $N$;

$N=5$

Once the $\% \mathrm{~K}$-line value is obtained, the $\% \mathrm{D}$-line value is calculated, which is a simple moving average a 10 period.

Figure 21 shows the attention signals that were activated when the average of short term descends below that of long term. (green triangles). Other attention signals were generated by crossing the fast and slow stochastic lines (red triangles) and by the magnitude values that were positioned above the downward trendline (red dotted line).

In Figure 22, we can see how the short term bands approach those of the long term moving averages and become a thread. This circumstance is the one that indicates a possible occurrence of an energy event.

The attention signal was generated by crossing the fast and slow stochastic lines (red triangles) and by the magnitude values that were placed above the downward trendline.

In Figure 23 we can observe how the group of short-term moving averages fell below the long-term one, during the phase of energy accumulation that ended with the occurrence of the foreshock of magnitude 6.1 Mw on 28/09/18. After the foreshock, the group of short term moving averages was brought over 
the long term one, generating a signal of attention. Another attention signal was activated when the magnitude values were above the downward trendline.

In Figure 24, the group of short-term moving averages moved over the group in the long run, indicating a phase of energy release. The attention signal was generated by crossing the fast and slow stochastic lines (red triangles) and by the magnitude values that are positioned above the downward trendline.

\section{Conclusions}

The study of seismic clusters can represent a useful approach for understanding the nucleation phenomenon of strong earthquakes. In fact, the retrospective analysis of the values of longitude, latitude and magnitude of several sequences showed the beginning of a critical state before a strong earthquake that can be exploited as a possible precursor.

Through the proposed model described this paper, it is possible to study the seismicity of an area and obtain information during the evolution of the seismic sequence. This information can be used as possible short-term precursors of strong earthquakes.

In particular, we have noticed that strong earthquakes are preceded by smaller events than in the series of latitude and longitude values generate irregular fluctuations, in which their amplitude increases progressively to a maximum value that depends on the size of the area analysed and the distribution of seismogenic structures.

Usually the strong earthquake occurs after the maximum fluctuation value has been reached, followed by a rapid reduction during which earthquakes tend to group together, forming clusters.

The organization in space and time of the values of longitude and latitude before a strong earthquake can be used, in some cases, to identify the most likely area where the strong earthquake will occur.

To identify significant changes in the values of longitude, latitude and magnitude and establish valid attention signals to be used for the study of earthquake forecasting, simple calculation procedures and graphics have been developed to identify the periods where most likely earthquakes will occur stronger.

Through this model of seismic sequence analysis it has been possible to obtain information that can be exploited as possible precursors of strong earthquakes. In effect the analyses have shown that the procedures developed provide fairly reliable information on the period of occurrence of the large earthquakes studied.

\section{Conflicts of Interest}

The authors declare no conflicts of interest regarding the publication of this paper.

\section{References}

[1] Huang, Q. (2015) Forecasting the Epicenter of a Future Major Earthquake. PNAS, 
112, 944-945. https://doi.org/10.1073/pnas.1423684112

[2] Jackson, D.D. (1995) Hypothesis Testing and Earthquake Prediction. In: Leon Knopoff, L., Aki, K., Allen, C.R., Rice, J.R. and Sykes, L.R., Eds., Earthquake Prediction: The Scientific Challenge, National Academy of Sciences, Irvine. https://www.nap.edu/read/5709/chapter/10

[3] Knopoff, L. (1995) A Selective Phenomenology of the Seismicity of Southern California. In: Leon Knopoff, L., Aki, K., Allen, C.R., Rice, J.R. and Sykes, L.R., Eds., Earthquake Prediction: The Scientific Challenge, National Academy of Sciences, Irvine. https://www.nap.edu/read/5709/chapter/8

[4] US Geological Survey (USGS): Search Earthquake Archives. http://earthquake.usgs.gov/earthquakes/search

[5] INGV (2017) Centro Nazionale Terremoti, Earthquake List. Database Updated to 2017. http://www.ingv.it/it/

[6] NIED Earthquake Mechanism Search: Search Earthquake Archives. http://www.fnet.bosai.go.jp/event/search.php?LANG=en

[7] Doglioni, C., Carminati, E., Petricca, P. and Riguzzi, F. (2015) Normal Fault Earthquakes or Graviquakes. Scientific Reports, 5, Article No. 12110. https://doi.org/10.1038/srep12110

[8] Petricca, P., Barba, S., Carminati, E., Doglioni, C. and Riguzzi, F. (2015) Graviquakes in Italy. Tectonophysics, 656, 202-214.

https://doi.org/10.1016/j.tecto.2015.07.001

[9] Balocchi, P. and Riga, G. (2017) Considerations on the Seismotectonics and Seismogenesis of Tiberina-Gubbio Valley Extensional System (Centrai Italy). Atti della Societa dei Naturalisti e Matematici di Modena, 148, 65-82.

[10] Wetzler, N., Sagy, A. and Marco, S. (2014) The Association of Micro-Earthquake Clusters with Mapped Faults in the Dead Sea Basin. Journal of Geophysical Research: Solid Earth, 119, 8312-8330. https://doi.org/10.1002/2013JB010877

[11] Balocchi, P., Lupoli, F.C. and Riga, G. (2016) La sequenza sismica dei monti del Chianti in Toscana e alcune considerazioni sulla struttura sismogenetica e il modello sismotettonico. Atti della Societa dei Naturalisti e Matematici di Modena, 147, 39-52.

[12] Mantovani, E., Viti, M., Babbucci, D., Tamburelli, C. and Cenni, N. (2016) Tentativo di identificazione delle zone sismiche italiane più esposte ai prossimi terremoti forti. Università di Siena.

https://www.dsfta.unisi.it/sites/st01/files/allegatiparagrafo/05-07-2016/tentativo_di_ identificazione.pdf

[13] Stein, R.S. (1999) The Role of Stress Trasfert in Earthquake Occurrence. Nature, 402, 605-609. https://doi.org/10.1038/45144 http://basin.earth.ncu.edu.tw/download/courses/seminar_MSc/2011/1229-1_02.pdf

[14] Walsh, J.J. and Watterson, J. (1988) Analysis of the Relationship between Displacements and Dimensions of Faults. Journal of Structural Geology, 10, 239-247. https://doi.org/10.1016/0191-8141(88)90057-0

[15] Riga, G. and Balocchi, P. (2016) Short-Term Earthquake Forecast with the Seismic Sequence Hierarchization Method. Open Journal of Earthquake Research, 5, 79-96. https://doi.org/10.4236/ojer.2016.52006

[16] Riga, G. and Balocchi, P. (2017) Aftershocks Identification and Classification. Open Journal of Earthquake Research, 6, 135-157. https://doi.org/10.4236/ojer.2017.63008

[17] Riga, G. and Balocchi, P. (2018) Double Earthquakes Classification and Seismic 
Precursors. Open Journal of Earthquake Research, 7, 1-27.

https://file.scirp.org/Html/1-2740149_82341.htm

https://doi.org/10.4236/ojer.2018.71001

[18] Utsu, T. (2002) Statistical Features of Seismicity. In: Lee, W.H.K., Kanamori, H., Jennings, P.C. and Kisslinger, C., Eds., International Handbook of Earthquake and Engineering Seismology, International Geophysics, Volume 81, Part A, Elsevier, Amsterdam, 719-732. https://doi.org/10.1016/S0074-6142(02)80246-7

[19] Riga, G. and Balocchi, P. (2016) How to Identify Foreshocks in Seismic Sequences to Predict Strong Earthquakes. Open Journal of Earthquake Research, 5, 55-71. http://file.scirp.org/pdf/OJER_2017022716403939.pdf https://doi.org/10.4236/ojer.2017.61003

[20] Guppy, D. (2004) Guppy Trading: Essential Methods for Modern Trading. John Wiley \& Sons Ltd., Hoboken.

[21] Barbara, R. (2011) Technical Analysis for Dummies. 2end Edition, Wiley Publishing, Inc., Hoboken.

https://the-eye.eu/public/Books/IT\%20Various/technical_analysis_for_dummies_2 nd_edition.pdf

[22] Di Napoli, J. (1998) Trading with Di Napoli Levels: The Practical Application of Fibonacci Analysis to Investment Markets, Coast Investment Software, Inc. and Joe Di Napoli.

http://dl.fxf1.com/books/english/DiNapoli,_Joe_-_Trading_with_DiNapoli_Levels_ ___The_Practical_Application_of_Fibonacci_Analysis.pdf 